\title{
Mathematical Model for Predicting the Rate of Human Happiness: A study of Federal University Wukari community of Nigeria
}

\author{
Ogwumu, Onah.David \\ Department of Mathematics and Statistics, Federal University Wukari, Nigeria \\ Corresponding Author: onahdavid2010@gmail.com, davidonah@fuwukari.edu.ng
}

\author{
Kyagya T.Yusuf, Amakoromo Grace.I., Keto, Kingsley M., Ezeh A.Tochukwu., Ogofotha Marvellous \\ O., Elugah Joseph.I. \\ Department of Mathematics and Statistics, Federal University Wukari, Nigeria \\ E-mail:tizhetizhekyagya@gmail.com,dabtgrace@yahoo.com,kings.keto5@gmail.com, \\ amoscotk0@gmail.com, marvellousovuzorie@gmail.com, joecalculus1@gmail.com
}

Received: 01 July 2020; Accepted: 15 July 2020; Published: 08 December 2020

\begin{abstract}
The research is concerned with the development of a mathematical model for predicting the rate of human happiness and to outline factors that influence human happiness. The model was optimized and observation about the model's extreme value was made. The outcome of the optimization result showed that happiness has neither minimum nor maximum level that should be required in human. It means someone's happiness could be close to $0 \%$ or even be up to $100 \%$. Thereafter, the model was analysed and the collated real-life data were correlated with those of the model data (H model) using suitable statistical tools. The findings from the correlation result showed that the questionnaire result attained a $70 \%$ degree of correlation with the estimated model result ( $\mathrm{H}$ model), and thus recommending the model as a standard measure for predicting the rate of human happiness.
\end{abstract}

Index Terms: Happiness, Model development, Age, Challenges, Optimization of the model, Correlation coefficient, Constant of integration

\section{Introduction}

For many people, the pursuit of happiness is a dominant goal of life, and countless books have been written in an attempt to help readers achieve this goal. However, happiness is almost certainly a dynamic process. The power of mathematics has rarely been applied to the dynamics of happiness, although some dynamical models of love, which is certainly one source of happiness, have been inspired by the important considerations of [1] essentially, the same model was described and studied by [2].

One might suppose that it is essential from the outset to define happiness, which embodies many emotions, including excitement, pleasure, joy, contentment, serenity, fulfilment, and satisfaction, among others [3]. Researchers like [4] have tried to distinguish between mood, which is not triggered by outside events, and emotions which is triggered by inward event. His effort to distinguish between them gave rise to the advancement of the Buddhist philosophy that true happiness is a mood not related to external circumstances. However, the model proposed by this study is not completely sensitive to the precise definition of happiness, since most people can readily decide whether they are happy at the moment and how happy or unhappy they were at various stages of their lives. Although there exist several preferential tendencies to report positive happiness, perhaps as a result of peer pressure [5].

In psychology, happiness of a person is a mental or emotional state of well-being that can be related to, positive or pleasant emotions of someone emanating from contentment and intense joy. Likewise, happy mental states could instigate judgements by a person about their overall well-being [6]

Moreover, a question may be asked: what is happiness? Can we say it is it pleasure? Or is it a life of prosperity? Or is it something else? Yet one cannot answer that question until we have some notion of what the word really meant. However, [7]described happiness as a world of well-being sense capable of making a value judgment considering the fact that a person has whatever it is that benefits himself and other humans or not. For instance, If you and I have different values, then we may well differ about which lives we consider happy or not. I might think Amos had a happy life, because I think 
what matters for well-being is getting what you want; while you may deny this because you think a life of evildoing, however "successful," is sad and impoverished.

A sequence of models for the time evolution of one's happiness in response to external events is described. These models with added nonlinearities can produce stable oscillations given the existence of some external events. Potential implications for psychotherapy and a personal approach to life are discussed. This research is meant to formulate a model equation showing how our happiness depends not only on what happens to us but also how this compares to other people.

The objectives of this research are: establish mathematical relationship between happiness and some key factors that influences happiness; validate the model results by correlating its value with real life data; and to optimize the model formulated and provide information that determines one's level of happiness.

\subsection{Motivations for the study}

There are a lot of issues that motivated this study.

- The first situation is the quest for happiness. Happiness is the most desired emotional feeling by all humans; many people go into different activities trying to be happy. People embark into relationships to be happy, people seek job opportunities to be happier than they have been, and people even go to the extreme of taking drugs that enhance "norepinephrine" (happiness hormone) such as ecstasy to get happiness. This desperate desire for happiness by humans prompted my enthusiasm to the study.

- Secondly, unavailability of mathematical tools to predict human's happiness in the existing literature. In this present technology powered world, any hope we might have of a reasonably human future in which cooperation and decency are incentivized may depend on our ability to represent our higher human needs mathematically, and to build these representations into the increasingly unfathomable systems that drive education, politics, well-being, and the economy.

- Another of the motivations for this study is academic contribution. Fellow researchers could learn from and also improve on this study from various standpoints.

\section{Literature Review}

Research shows that happiness is not the result of bouncing from one joy to the next but achieving happiness could typically involve times of considerable discomfort. Money is important to happiness, but only to a certain point. Money buys freedom from worry about the basics in life like: housing, food and clothing. Also genetic makeup, life circumstances, achievements, marital status, social relationships, even your neighbours; all influence how happy you are or can be, [8].

According to [9], a failsafe way of sustaining high happiness levels is to maintain low expectations. This formula is based on the idea that one's happiness levels are inversely proportional to one's expectations. Furthermore, [10] suggested that happiness is a default state. If we shape expectations to acknowledge the full range of possible events, unhappiness is on its way to being defeated.

Happiness reflects not just the aggregate of moments in one's life, but also the global quality of one's life taken as a whole, [11]. And we seem to care not just about the total quantity of good in our lives, but about its distribution. a happy ending, say, counts for more than a happy middle, [12].

Economists thought that challenges like unemployment usually caused a strong sense of unhappiness. [13] Used the data from British Household Panel Study and realise that the unemployed people happiness sense is lower than the employed ones. Moreover, unemployment has a larger influence on lowering happiness than divorce.Lastly, researchers like [14] stipulated that, as we age, we have the opportunity to accept who we are, instead of focusing on who we feel we need to become. We relax into being ourselves. Our faces start to look like who we are. And the world settles into more and more familiar patterns. That acceptance brings diminished anxiety and a higher degree of enjoyment.

\section{Research Methodology}

\subsection{Model Formulation}

To create the research model equation, we considered some measurable parameters that strongly influence human happiness, and the mathematical relationship between happiness and these parameters were established. However, under this section, we employed some basic assumptions needed to give us a model that conforms to reality.

\subsubsection{Some Basic Assumptions for the Model}

\subsubsection{Happiness $(H)$ versus Challenges $(N)$ faced by Humans}

In this research we refer challenges as factors that reduce happiness of a person; factors like bad news, death, loss, and so on. We denote these challenges factor by $\mathrm{N}$. Since an increase in $\mathrm{N}$ will lead to a drastic reduction in Happiness $\mathrm{H}$, then 
we can remark that the relationship between $\mathrm{H}$ and $\mathrm{N}$ is an inverse proportionality relationship. Thus mathematically, we have;

$$
\begin{aligned}
& H \propto \frac{1}{N} \\
& H=\frac{C_{2}}{N}
\end{aligned}
$$

Where $C_{2}$ is the constant of proportionality.

\subsubsection{Happiness versus Age of Humans}

Research has shown that when people are young, they tend to be happier because they have little or no worries, and as they grow into their working or youth stage of life their happiness level reduces. And similarly, their happiness level increases again as they become older since it is assumed that at this stage, they would have enough children, friends and family member to help shoulder their needs. This results into a quadratic relationship between happiness and age. And if we denote age by A; then,

$$
H=a A^{2}+b A+d
$$

Where a, b, and d are constants to be determined.

\subsubsection{Establishment of model parameter Relationship}

Let by combining via addition of equation (2) and (3) gives;

Let

$$
\begin{aligned}
& 2 H=\frac{c_{2}}{N}+a A^{2}+b A+d \\
& \Rightarrow H=\frac{c}{2 N}+\frac{a}{2 A^{2}}+\frac{b}{2 A}+\frac{d}{2} \\
& \frac{c}{2}=c, \frac{a}{2}=a, \frac{b}{2}=b, \text { and } \frac{d}{2}=d \\
& H(t)=\frac{c}{N}+a A^{2}+b A+d
\end{aligned}
$$

Where; $\mathrm{N}$ = challenges, $\mathrm{A}$ = Age, and a, b, c, d are all constants to be evaluated.

\subsection{Computation of the Model Equation Constants}

We apply least Squares method on equation (5) so as to obtain the values for our model equation constants.

$$
Z_{\min }=\sum_{(i=1)}^{n}\left[H_{i}(t)-\frac{c}{N}-a A_{i}^{2}-b A_{i}-d\right]^{2}
$$

Where $\mathrm{i}=1,2,3 \ldots \ldots, \mathrm{n}$. but for this study $\mathrm{n}=38$. And likewise, at optimal point

$$
\frac{\partial Z}{\partial c}=\frac{\partial Z}{\partial a}=\frac{\partial Z}{\partial b}=\frac{\partial Z}{\partial d}=0
$$

Thus, differentiating equation (8) partially with respect to each of the distinct model constants and equating to zero yields

$$
\frac{\partial Z}{\partial c}=-2 \sum_{(i=1)}^{38}\left[H_{i}(t)-\frac{c}{N}-a A_{i}^{2}-b A_{i}-d\right] * \frac{1}{N}
$$

Setting equation (10) to zero yields; 


$$
\begin{gathered}
\sum_{(i=1)}^{38}\left[H_{i}(t)-\frac{c}{N}-a A_{i}^{2}-b A_{i}-d\right] * \frac{1}{N}=0 \\
\Rightarrow \sum_{(i=1)}^{38} \frac{1}{N_{i}} * H_{i}(t)-\sum_{i=1}^{38} \frac{c}{N_{i}^{2}}-\sum_{i=1}^{38} a A_{i}^{2} * \frac{1}{N_{i}}-\sum_{(i=1)}^{38} b A_{i} * \frac{1}{N_{i}}-\sum_{(i=1)}^{38} d * \frac{1}{N_{i}}=0
\end{gathered}
$$

Similarly,

$$
\begin{gathered}
\frac{\partial Z}{\partial a}=-2 \sum_{(i=1)}^{38}\left[H_{i}(t)-\frac{c}{N_{i}}-a A_{i}^{2}-b A_{i}-d\right] * A_{i}^{2}=0 \\
\Rightarrow \sum_{(i=1)}^{38} A_{i}^{2} * H_{i}(t)-\sum_{(i=1)}^{38} \frac{c}{N_{i}} * A_{i}^{2}-\sum_{(i=1)}^{38} a A_{i}^{4}-\sum_{(i=1)}^{38} b A_{i}^{3}-\sum_{(i=1)}^{38} d * A_{i}^{2}=0 \\
\frac{\partial Z}{\partial b}=-2 \sum_{(i=1)}^{38}\left[H_{i}(t)-\frac{c}{N_{i}}-a A_{i}^{2}-b A_{i}-d\right]^{*} A_{i}=0 \\
\Rightarrow \sum_{(i=1)}^{38} A_{i}^{*} H_{i}(t)-\sum_{(i=1)}^{38} \frac{c}{N_{i}} * A_{i}-\sum_{(i=1)}^{38} a A_{i}^{3}-\sum_{(i=1)}^{38} b A_{i}^{2}-\sum_{(i=1)}^{38} d^{*} A_{i}=0 \\
\frac{\partial Z}{\partial d}=-2 \sum_{(i=1)}^{38}\left[H_{i}(t)-\frac{c}{N_{i}}-a A_{i}^{2}-b A_{i}-d\right]=0 \\
\Rightarrow \sum_{(i=1)}^{38} H_{i}(t)-\sum_{(i=1)}^{38} \frac{c}{N_{i}}-\sum_{(i=1)}^{38} a A_{i}^{2}-\sum_{(i=1)}^{38} b^{*} A_{i}-\sum_{(i=1)}^{38} d=0
\end{gathered}
$$

\subsection{Research Instrument Used}

The research made use of primary data in order to present a more objective view at the end of the study. Primary data are those data obtained for the solution of specific problem at hand. This kind of data could be obtained from primary sources through the use of questionnaires and oral interview, so as to obtain real data from individual respondents. Thus, the research instrument used for data collection of this study is the interview and questionnaire method. This is because we want to get how happy people are and what really make them that happy. Specifically, we adopted purposeful sampling since we want to focus on Federal University Wukari community. A total of 300 questionnaires were distributed in different part of Nigeria places like wukari in Taraba, some part Enugu state and of Anambra state. And after analysis and critical evaluations of the data obtained a total of 38 questionnaires were used for our data analysis while others were discarded due to fake response, multiple shading of options, and incomplete answers.

\subsection{Evaluation of Equation Constants using the Data in Table1. Above}

Here, we perform algebraic multiplication and divisions on the data in Table 1.above and apply the outcome into equation (11), (12), (13) and (14) in order to obtain the models constants yields;

$$
\begin{gathered}
830.9125=165659 c+1165001.0429 a+32385.42 b+1190.833 d \\
33571.78=1165001.042 c+140871751.9 a+2782504 b+58882.75 d \\
774.3775=32385.42 c+2782504 a+58882.75 b+1380.5 d \\
20.99=1190.833 c+58882.75 a+1380.5 b+38 c
\end{gathered}
$$


Table 1.: Questionnaire Data gathered for the Research.

\begin{tabular}{|c|c|c|c|}
\hline Respondents & Age (A) & Challenge $(\mathrm{N})$ & Happiness $(\mathrm{H})$ \\
\hline 1 & 60 & 0.1 & 0.655 \\
\hline 2 & 30.5 & 0.15 & 0.455 \\
\hline 3 & 5 & 0.005 & 0.755 \\
\hline 4 & 50.5 & 0.05 & 0.555 \\
\hline 5 & 60 & 0.15 & 0.655 \\
\hline 6 & 50.5 & 0.05 & 0.455 \\
\hline 7 & 15.5 & 0.15 & 0.455 \\
\hline 8 & 30.5 & 0.15 & 0.455 \\
\hline 9 & 40.5 & 0.2 & 0.555 \\
\hline 10 & 60 & 0.1 & 0.655 \\
\hline 11 & 40.5 & 0.05 & 0.555 \\
\hline 12 & 30.5 & 0.005 & 0.855 \\
\hline 13 & 30.5 & 0.05 & 0.555 \\
\hline 14 & 30.5 & 0.005 & 0.955 \\
\hline 15 & 30.5 & 0.1 & 0.455 \\
\hline 16 & 40.5 & 0.05 & 0.555 \\
\hline 17 & 40.5 & 0.1 & 0.355 \\
\hline 18 & 30.5 & 0.1 & 0.455 \\
\hline 19 & 15.5 & 0.2 & 0.455 \\
\hline 20 & 15.5 & 0.005 & 0.555 \\
\hline 21 & 30.5 & 0.1 & 0.555 \\
\hline 22 & 30.5 & 0.3 & 0.555 \\
\hline 23 & 60 & 0.05 & 0.555 \\
\hline 24 & 50.5 & 0.2 & 0.555 \\
\hline 25 & 30.5 & 0.1 & 0.355 \\
\hline 26 & 15.5 & 0.1 & 0.455 \\
\hline 27 & 15.5 & 0.1 & 0.555 \\
\hline 28 & 30.5 & 0.05 & 0.455 \\
\hline 29 & 30.5 & 0.4 & 0.355 \\
\hline 30 & 30.5 & 0.1 & 0.655 \\
\hline 31 & 50.5 & 0.1 & 0.755 \\
\hline 32 & 50.5 & 0.15 & 0.655 \\
\hline 33 & 15.5 & 0.15 & 0.355 \\
\hline 34 & 60 & 0.05 & 0.655 \\
\hline 35 & 50.5 & 0.05 & 0.455 \\
\hline 36 & 30.5 & 0.1 & 0.655 \\
\hline 37 & 60 & 0.05 & 0.455 \\
\hline 38 & 30.5 & 0.1 & 0.555 \\
\hline & $\sum_{i=1}^{38} A_{i}=1380.5$ & $\sum_{i=1}^{38} N_{i}=4.02$ & $\sum_{i=1}^{38} H_{i}=20.99$ \\
\hline
\end{tabular}

Source: data obtained from the field using the questionnaire.

Hence, by solving equation (15), (16), (17), and (18) simultaneously by Gauss elimination method, we obtain: 


$$
\begin{aligned}
& c=0.001648534644 \\
& a=-0.00001124652393 \\
& b=0.004237760047 \\
& d=0.3641807646
\end{aligned}
$$

Thus, putting the values of a,b, c, and d, into equation (19) we have;

$$
H=\frac{0.001648534644}{N}-0.0001124652393 A^{2}+0.004237760047 A+0.3641807646
$$

Equation (20) is the developed model for predicting the rate of human happiness.

\section{Discussion of Results}

This section is the reflection of the discussion of findings in the research where the data gathered and model formulated are presented and analysed, at the end of the previous chapter, we were able to gather data by questionnaire in order to evaluate the models constants. Hence the formulated model is:

$$
H(t)=\frac{c}{N}+a A^{2}+b A+d
$$

Were:

$$
\begin{aligned}
& c=0.001648534644 \\
& a=-0.00001124652393 \\
& b=0.004237760047 \\
& d=0.3641807646
\end{aligned}
$$

\subsection{Optimization of the Model}

Mathematical optimization is the selection of a best element (with regard to some criterion) from some set of available alternatives. In the simplest case, an optimization problem consists of maximizing or minimizing a real function by systematically choosing input values from within an allowed set and computing the value of the function. More generally, optimization includes finding "best available" values of some objective function given a defined domain (or input), including a variety of different types of objective functions and distinct domains.

Hence, we will wish to optimize our result by using Lagrange's multiplier method subject to a particular constrain as follows:

From equation (21) in the previous chapter,

$$
H(t)=\frac{c}{N}+a A^{2}+b A+d
$$

Since our model equation is in 2-variable (age and challenge), we then determine the nature of its extreme values.

\subsection{Observation on the Nature of the Model Extreme Values}

In this stage, we test if the models extreme point or limit point is at minimum, maximum, or saddle point.

Generally, given any continuous function $U(x, y)$ satisfying continuity of functional partial derivatives; then letting:

When:

$$
A=\frac{\partial^{2} U}{\partial x^{2}} ; B=\frac{\partial^{2} U}{\partial x \partial y} ; C=\frac{\partial^{2} U}{\partial y^{2}}
$$


1. $B^{2}-A C<0$, it implies that $U(x, y)$ has extreme value $\left(x_{0}, y_{0}\right)$ and minimum if $A>0$, and it is maximum if $A<0$.

2. $B^{2}-A C>0$, or $A B<C^{2}$ it implies that $U(x, y)$ has no extreme value. And it implies that the point $\left(x_{0}, y_{0}\right)$ it is saddle.

3. $B^{2}-A C=0$, it implies that one has no knowledge about its extreme values.

Thus, applying the above rule to our model equation we have:

$$
\begin{gathered}
\frac{\partial H}{\partial A}=2 a A+b \\
\Rightarrow A=\frac{\partial^{2} H}{\partial A^{2}}=2 a \\
\text { also, } \frac{\partial H}{\partial N}=\frac{-C}{N^{2}} \\
\Rightarrow C=\frac{\partial^{2} H}{\partial N^{2}}=\frac{2 c}{N^{3}} \\
\text { finally, } B=\frac{\partial^{2} H}{\partial A \partial N}=\frac{\partial}{\partial A}\left(\frac{-C}{N}\right)=0
\end{gathered}
$$

Therefore from the above rule,

$$
B^{2}-A C=0-2 a\left(\frac{2 c}{N^{3}}\right)=\frac{-4 a c}{N^{3}}
$$

Recall that;

$$
\begin{gathered}
c=0.001648534644 \\
a=-0.00001124652393
\end{gathered}
$$

Thus,

$$
B^{2}-A C=\frac{0.00000001854}{N^{3}}>0
$$

Hence, from (29) we can conclude that there is neither maximum nor minimum level of happiness for human. It therefore implies that happiness level of a person can grow close to $100 \%$ and could drop down to a level as close to $0 \%$. From the findings of the study also, we can infer that happiness of every individual at the initial point (Birth) is equivalent to zero; as no age and challenge has been recorded at that point.

\subsection{Validation of the Model}

A model is developed for a specific purpose (or application) and its validity determined with respect to that purpose. If the purpose of a model is to answer a variety of questions, the validity of the model needs to be determined with respect to each question, [15]

For the model to be ready we have to test if it conforms to reality by conducting a pilot test on the data obtained in the various area of the research. The test show that the model conforms to reality since the absolute difference between the questionnaire's data and the actual model's data is less than $20 \%$ (as shown in the Table 2 below), the minor error in the actual model data is as a result of the other factors that affects happiness which is not captured in this research.

Furthermore, given that what constitutes a good model is subjective, but from a performance modelling point of view our criteria for judging the goodness of models will be based on how accurately measures extracted from the model correspond to the measures which would be obtained from the represented system, [16].The Table below give a validation of the questionnaire data to check if the model actually calculates happiness or not; and whether the model should be an approved mathematical model for predicting the rate of human happiness, and also show the absolute error. 
Table 2.: Table for the Validation of the Model

\begin{tabular}{|c|c|c|c|}
\hline $\mathrm{H}$ & $H_{M}$ & Absolute difference & Percentage difference \\
\hline 0.655 & 0.594444228 & 0.060555772 & 6.055577 \\
\hline 0.455 & 0.493960598 & 0.038960598 & 3.89606 \\
\hline 0.755 & 0.714795331 & 0.040204669 & 4.020467 \\
\hline 0.555 & 0.582476892 & 0.027476892 & 2.747689 \\
\hline 0.655 & 0.588949112 & 0.066050888 & 6.605089 \\
\hline 0.455 & 0.582476892 & 0.127476892 & 12.74769 \\
\hline 0.455 & 0.438154299 & 0.016845701 & 1.68457 \\
\hline 0.455 & 0.493960598 & 0.038960598 & 3.89606 \\
\hline 0.555 & 0.525605609 & 0.029394391 & 2.939439 \\
\hline 0.655 & 0.594444228 & 0.060555772 & 6.055577 \\
\hline 0.555 & 0.550333629 & 0.004666371 & 0.466637 \\
\hline 0.855 & 0.812677296 & 0.042322704 & 4.23227 \\
\hline 0.555 & 0.51594106 & 0.03905894 & 3.905894 \\
\hline 0.955 & 0.812677296 & 0.142322704 & 14.23227 \\
\hline 0.455 & 0.499455714 & 0.044455714 & 4.445571 \\
\hline 0.555 & 0.550333629 & 0.004666371 & 0.466637 \\
\hline 0.355 & 0.533848282 & 0.178848282 & 17.88483 \\
\hline 0.455 & 0.499455714 & 0.044455714 & 4.445571 \\
\hline 0.455 & 0.435406741 & 0.019593259 & 1.959326 \\
\hline 0.555 & 0.756870997 & 0.201870997 & 20.1871 \\
\hline 0.555 & 0.499455714 & 0.055544286 & 5.554429 \\
\hline 0.555 & 0.488465483 & 0.066534517 & 6.653452 \\
\hline 0.555 & 0.610929574 & 0.055929574 & 5.592957 \\
\hline 0.555 & 0.557748873 & 0.002748873 & 0.274887 \\
\hline 0.355 & 0.499455714 & 0.144455714 & 14.44557 \\
\hline 0.455 & 0.443649414 & 0.011350586 & 1.135059 \\
\hline 0.555 & 0.443649414 & 0.111350586 & 11.13506 \\
\hline 0.455 & 0.51594106 & 0.06094106 & 6.094106 \\
\hline 0.355 & 0.487091704 & 0.132091704 & 13.20917 \\
\hline 0.655 & 0.499455714 & 0.155544286 & 15.55443 \\
\hline 0.755 & 0.565991546 & 0.189008454 & 18.90085 \\
\hline 0.655 & 0.56049643 & 0.09450357 & 9.450357 \\
\hline 0.355 & 0.438154299 & 0.083154299 & 8.31543 \\
\hline 0.655 & 0.610929574 & 0.044070426 & 4.407043 \\
\hline 0.455 & 0.582476892 & 0.127476892 & 12.74769 \\
\hline 0.655 & 0.499455714 & 0.155544286 & 15.55443 \\
\hline 0.455 & 0.610929574 & 0.155929574 & 15.59296 \\
\hline 0.555 & 0.499455714 & 0.055544286 & 5.554429 \\
\hline
\end{tabular}

Remarks: it is clear from the Table 2 above that our real life gathered data $(\mathrm{H})$ on happiness of humans approximately coincided with the model results $\left(H_{M}\right)$ as shown. The results for $H_{M}$ is obtained by substituting each respondent data in table1 into equation (20). Similarly, observations from the difference between the two results therefore suggest how high our developed model is performing and thus recommends the model as a standard measurement for computing the rate of human happiness. 
Table 3: Correlation Coefficient between Questionnaire Data and Model Predicted Happiness

\begin{tabular}{|c|c|c|c|c|}
\hline $\mathrm{H}$ & $H_{M}$ & $\boldsymbol{H} * \boldsymbol{H}_{\boldsymbol{M}}$ & $H^{2}$ & $H_{m}^{2}$ \\
\hline 0.655 & 0.594444228 & 0.389360969 & 0.429025 & 0.35336394 \\
\hline 0.455 & 0.493960598 & 0.224752072 & 0.207025 & 0.243997072 \\
\hline 0.755 & 0.714795331 & 0.539670475 & 0.570025 & 0.510932365 \\
\hline 0.555 & 0.582476892 & 0.323274675 & 0.308025 & 0.33927933 \\
\hline 0.655 & 0.588949112 & 0.385761669 & 0.429025 & 0.346861057 \\
\hline 0.455 & 0.582476892 & 0.265026986 & 0.207025 & 0.33927933 \\
\hline 0.455 & 0.438154299 & 0.199360206 & 0.207025 & 0.19197919 \\
\hline 0.455 & 0.493960598 & 0.224752072 & 0.207025 & 0.243997072 \\
\hline 0.555 & 0.525605609 & 0.291711113 & 0.308025 & 0.276261256 \\
\hline 0.655 & 0.594444228 & 0.389360969 & 0.429025 & 0.35336394 \\
\hline 0.555 & 0.550333629 & 0.305435164 & 0.308025 & 0.302867103 \\
\hline 0.855 & 0.812677296 & 0.694839088 & 0.731025 & 0.660444387 \\
\hline 0.555 & 0.51594106 & 0.286347288 & 0.308025 & 0.266195177 \\
\hline 0.955 & 0.812677296 & 0.776106818 & 0.912025 & 0.660444387 \\
\hline 0.455 & 0.499455714 & 0.22725235 & 0.207025 & 0.24945601 \\
\hline 0.555 & 0.550333629 & 0.305435164 & 0.308025 & 0.302867103 \\
\hline 0.355 & 0.533848282 & 0.18951614 & 0.126025 & 0.284993988 \\
\hline 0.455 & 0.499455714 & 0.22725235 & 0.207025 & 0.24945601 \\
\hline 0.455 & 0.435406741 & 0.198110067 & 0.207025 & 0.18957903 \\
\hline 0.555 & 0.756870997 & 0.420063403 & 0.308025 & 0.572853706 \\
\hline 0.555 & 0.499455714 & 0.277197921 & 0.308025 & 0.24945601 \\
\hline 0.555 & 0.488465483 & 0.271098343 & 0.308025 & 0.238598528 \\
\hline 0.555 & 0.610929574 & 0.339065914 & 0.308025 & 0.373234945 \\
\hline 0.555 & 0.557748873 & 0.309550624 & 0.308025 & 0.311083805 \\
\hline 0.355 & 0.499455714 & 0.177306778 & 0.126025 & 0.24945601 \\
\hline 0.455 & 0.443649414 & 0.201860484 & 0.207025 & 0.196824803 \\
\hline 0.555 & 0.443649414 & 0.246225425 & 0.308025 & 0.196824803 \\
\hline 0.455 & 0.51594106 & 0.234753182 & 0.207025 & 0.266195177 \\
\hline 0.355 & 0.487091704 & 0.172917555 & 0.126025 & 0.237258328 \\
\hline 0.655 & 0.499455714 & 0.327143492 & 0.429025 & 0.24945601 \\
\hline 0.755 & 0.565991546 & 0.427323617 & 0.570025 & 0.32034643 \\
\hline 0.655 & 0.56049643 & 0.367125162 & 0.429025 & 0.314156248 \\
\hline 0.355 & 0.438154299 & 0.155544776 & 0.126025 & 0.19197919 \\
\hline 0.655 & 0.610929574 & 0.400158871 & 0.429025 & 0.373234945 \\
\hline 0.655 & 0.582476892 & 0.265026986 & 0.207025 & 0.33927933 \\
\hline 0.655 & 0.499455714 & 0.327143492 & 0.912025 & 0.24945601 \\
\hline 0.455 & 0.610929574 & 0.277972956 & 0.207025 & 0.373234945 \\
\hline 0.555 & 0.499455714 & 0.277197921 & 0.308025 & 0.24945601 \\
\hline$\sum_{i=1}^{38} H_{i}=$ & $\sum_{i=}^{38} H_{M i}=$ & $\begin{array}{l}\sum_{i=1}^{38} H_{I} * H_{M i}= \\
11.91800254\end{array}$ & $\sum_{i=1}^{38} H_{i}^{2}=$ & $\sum_{\substack{i=1 \\
11.91800298}}^{38} H_{M i}^{2}=$ \\
\hline
\end{tabular}




$$
\begin{aligned}
& \text { Correlation coefficient }(\mathrm{r})=\frac{n \sum x y-\sum x \sum y}{\sqrt{\left[n \sum x^{2}-\left(\sum x\right)^{2}\right]\left[n \sum y^{2}-\left(\sum y\right)^{2}\right]}} \\
& r=\frac{38 * 11.91800254-20.99 * 20.99000055}{\sqrt{\left[38 * 12.26395-20.99^{2}\right]\left[38 * 11.91800298-20.99000055^{2}\right]}} \\
& r=0.6953
\end{aligned}
$$

Remarks: the outcome of the correlation coefficient analysis carried out using the data in Table 3 shows that $r=$ 0.6953. Thus we assert that our model has approximately $70 \%$ of correlation with real life data used. Finally, since our model has a high level of correlation with real life data, we are thus commending the model as a standard model for predicting the rate of human happiness.

\section{CONCLUSION}

This research work studied human happiness, factors that affect human happiness and the mathematical relationship between these factors and how they influence human happiness in Nigeria.

Primary data were collected using questionnaire as a tool. These data were collected from individuals from different background and opinion. In the study, we also harmonize the cumbersome data obtained using least-squares' method to obtain the proposed model equation constants.

After formulating the model, we validated the accuracy of the model by comparing its estimated result and real life data and found out that the model has a higher correlation with reality data used.

From the various level of the model analysis, this study has established that happiness is a vital goal that every human being should desire to pursue and achieve. And in order to attain a higher degree of happiness, one has to take cognizance of those factors that affects and influence happiness as highlighted in this study. It is instructive to note that this study has categorized the factors that affect happiness into two: (i) human factors and (ii) natural factors. The human factors are those factors that can be controlled by human (such as challenges) while the natural factors are those caused by nature and are beyond the control of human (i.e. age)

As an advantage of the study, it is obvious that with the formulated model in equation (20), any person can input his/her data into the model and obtain their happiness level. Equally, the optimization result of the model in equation (29) showed that there is neither maximum nor minimum level of happiness that humans should have at any time, it then means that someone can have or attain a happiness level close to $100 \%$ or $0 \%$. But the snag indicated by the study is that government and non-governmental remedies or programmes tailored towards reducing the challenge ratio of humans thereby bringing people to a happiness level that is close to $100 \%$ should be put in place. This is because people in this situation can take to violence, terrorism group formation, commit suicide, murder and even constitute seasonal threat to the society.

\section{References}

[1] M. Buchibrand, 7 forms of divorce in Africa, Retrieved on 22nd May 2018 from https://www.nairaland.com/2526539/7-formsdivorce-africa, 2016.

[1] S. H. Strogatz, "Love affairs and differential equations”, Mathematics magazine; 1994, 61: 35.

[2] M. J. Radzicki, "Dyadic processes, tempestuous relationships, and system dynamics,” System Dynamics Review, 1993; 9: 79-94.

[3] F. Orsucci, "Happiness and deep ecology: On noise, harmony, and beauty in the mind", Nonlinear Dynamics, Psychology, and Life Sciences ,2001; 5: 65-76.

[4] D. Goleman, "Destructive emotions: A scientific dialogue with the Dalai Lama”, New York: Bantum, 2003.

[5] E. Diener, E. Suh, R. Lucas \& H. Smith, ”Subjective well-being: Three decades of progress”, Psychological Bulletin, 1999; 125: 276-302.

[6] P. Anand, Happiness Explained. Oxford University Press, retrieved online, 2016.

[7] D. Haybron, "Happiness", The Stanford Encyclopedia of Philosophy, 2011; 1: 1-45. retrieved:https://plato.stanford.edu/archives/fall2011/entries/happiness/>.

[8] B. Blalock, "LIVING YOUR LEGACY NOW: inspiring life lessons for a successful, healthy and fulfilling life". DOG EAR Publishing, 2018.

[9] R. Raghunathan, “ The Pursuit of Happiness: Can It Make You Happy?”, PsycEXTRA Dataset, 2018.

[10] M. Gawdat, "Solve for Happy”, Pan Macmillan, 2019.

[11] J. Raibley, "Well-being and the priority of values," Social Theory and Practice, 2010; 36(4): 593.

[12] J. D. Velleman, “Well-Being and Time,” Pacific Philosophical Quarterly, 1991; 72(1): 48-77.

[13] A. Clark and A. Oswald, “unhappiness and unemployment”. Economic journal, 1994; 104(424): 648-59.

[14] K. Eisold, "why are we happier as we age". Happiness and age. Retrieved from: https://www.psychologytoday.com/intl/blog/hidden-motives/201006/happiness-and-age, 
[15] R. G. Sargent, '’Verification and Validation Of Simulation Models', Proceedings of the Winter Simulation Conference, 2011. [16] J. Hillston, “ PEPA nets: a structured performance modelling formalism”. Performance Evaluatio, .retrieved: http://www.inf.ed.ac.uk/teaching/courses/ms/notes/note14.pdf, 2003.

\section{Authors' Profiles}

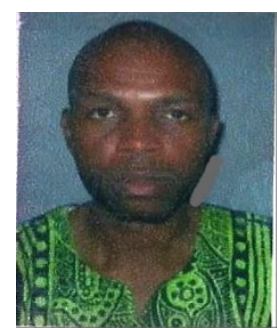

OGWUMU O.D. is currently employed as a Lecturer in the Department of Mathematics and Statistics, Faculty of Pure and Applied Science, Federal University Wukari, Nigeria. He obtained his Ph.D. from the University of Ilorin, Nigeria. He is an active researcher coupled with a vast teaching experience. He has taught various courses such as Mathematical Modelling, Mathematical Methods, Differential Equations, Optimisation Theory, Vectors and Tensor Analysis, Algebra and Trigonometry. His main research interests ranges from Mathematical Modelling, Differential Equations, optimization and control. He has published more than 35 research articles (including Text books) in reputed international journals and publishing houses.

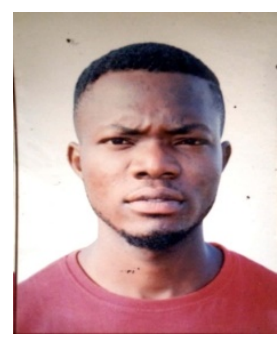

Ezeh A.T. holds a BSc Degree in Mathematics from the Department of Mathematics, Federal University Wukari, Nigeria. He is a First Class Graduate with main research interest in the area of Mathematical Modelling, Optimisation and Differential Equations. He has published some good research articles in both reputed international/national journals and publishing houses

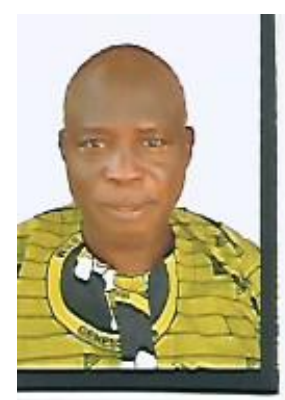

Kyagya T. Y. is currently employed as a Lecturer in the Department of Mathematics and Statistics, Faculty of Pure and Applied Science, Federal University Wukari, Nigeria. He holds a MSc. from the University of Jos Nigeria and has his Ph.D. (in view) from Adamawa State University Mubi, Nigeria. He is equally an active researcher coupled with a vast teaching experience in applied mathematics. His major research interest is in the area of Numerical Analysis and formulation of computational methods for Differential Equations.

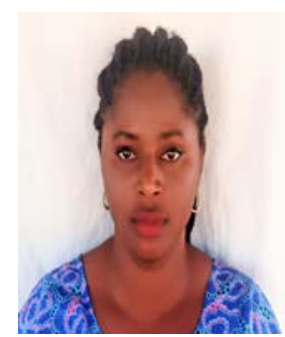

Amakoromo G.I. is a staff of Federal University Wukari, Nigeria in the Department of Mathematics and Statistics, Faculty of Pure and Applied Science. She holds a BSc. from the University of Jos Nigeria and has her MSc. (in view) from Nasarawa State Universit, Nigeria. Her research interest is in the area of Mathematical Modelling and Differential Equations. She has published some good research articles in both reputed international/national journals and publishing houses

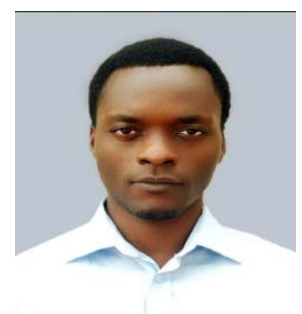

Keto, K. M. holds a BSc Degree in Mathematics from the Department of Mathematics, Federal University Wukari, Nigeria. He is one of the best researchers of his set in his undergrduate days. His main research interest is in the area of Mathematical Modelling and Differential Equations. He has published some good research articles in both reputed international/national journals and publishing houses 


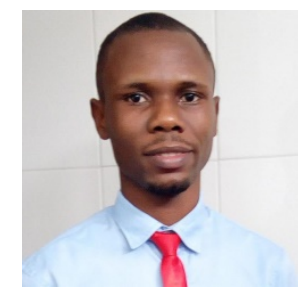

Ogofotha M. O. holds a BSc Degree in Mathematics from the Department of Mathematics, Federal University Wukari, Nigeria. He is one of the best students of his set in his undergrduate days. His main research interest is in the area of Mathematical Modelling and Differential Equations. He has published some good research articles in both reputed international/national journals and publishing houses

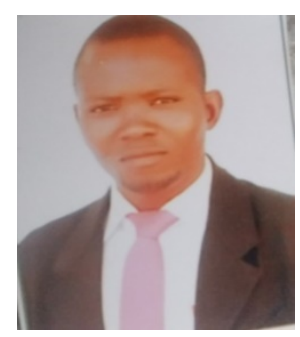

Elugah J.I. holds a BSc Degree in Mathematics from the Department of Mathematics, Federal University Wukari, Nigeria. He is one of the best students of his set in his undergrduate days. His main research interest is in the area of Fluid Mechanics and Differential Equations. He has published some good research articles in both reputed international/national journals and publishing houses

How to cite this paper: Ogwumu Onah.David, Kyagya T.Yusuf, Amakoromo Grace.I., Keto, Kingsley M., Ezeh A.Tochukwu., Ogofotha Marvellous O., Elugah Joseph.I.. " Mathematical Model for Predicting the Rate of Human Happiness: A study of Federal University Wukari community of Nigeria ", International Journal of Mathematical Sciences and Computing (IJMSC), Vol.6, No.6, pp.30-41, 2020. DOI: 10.5815/IJMSC.2020.06.05 